\title{
Congenital megacalycosis
}

INSERM

\section{Source}

INSERM. (1999). Orphanet: an online rare disease and orphan drug data base. Congenital megacalycosis. ORPHA:93109

Cong enital megacalycosis is a rare renal malformation, characterized by non-obstructive dilation of the renal calyces as well as an increased calyceal number (12-20), with a normal renal pelvis, ureter, and bladder. It may be unilateral or bilateral and is usually asymptomatic unless complicated by nephrolithiasis and urinary tract infection. 